\title{
Prevalence estimates of chronic kidney disease in Canada: results of a nationally representative survey
}

\author{
Paul Arora MSc, Priya Vasa MSc MD, Darren Brenner PhD, Karl Iglar MD, Phil McFarlane MD PhD, \\ Howard Morrison PhD, Alaa Badawi PhD
}

\begin{abstract}
Background: Chronic kidney disease is an important risk factor for death and cardiovascular-related morbidity, but estimates to date of its prevalence in Canada have generally been extrapolated from the prevalence of end-stage renal disease. We used direct measures of kidney function collected from a nationally representative survey population to estimate the prevalence of chronic kidney disease among Canadian adults.
\end{abstract}

Methods: We examined data for 3689 adult participants of cycle 1 of the Canadian Health Measures Survey (2007-2009) for the presence of chronic kidney disease. We also calculated the age-standardized prevalence of cardiovascular risk factors by chronic kidney disease group. We cross-tabulated the estimated glomerular filtration rate (eGFR) with albuminuria status.

Results: The prevalence of chronic kidney disease during the period 2007-2009 was $12.5 \%$, representing about 3 million Canadian adults. The estimated prevalence of stage 3-5 disease was $3.1 \%$ ( 0.73 million adults) and albuminuria $10.3 \%$ ( 2.4 million adults). The prevalence of diabetes, hypertension and hypertriglyceridemia were all significantly higher among adults with chronic kidney disease than among those without it. The prevalence of albuminuria was high, even among those whose eGFR was $90 \mathrm{~mL} / \mathrm{min}$ per $1.73 \mathrm{~m}^{2}$ or greater $(10.1 \%)$ and those without diabetes or hypertension (9.3\%). Awareness of kidney dysfunction among adults with stage 3-5 chronic kidney disease was low (12.0\%).

Interpretation: The prevalence of kidney dysfunction was substantial in the survey population, including individuals without hypertension or diabetes, conditions most likely to prompt screening for kidney dysfunction. These findings highlight the potential for missed opportunities for early intervention and secondary prevention of chronic kidney disease.

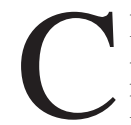

hronic kidney disease is defined as the presence of kidney damage or reduced kidney function for more than 3 months and requires either a measured or estimated glomerular filtration rate (eGFR) of less than $60 \mathrm{~mL} / \mathrm{min}$ per $1.73 \mathrm{~m}^{2}$, or the presence of abnormalities in urine sediment, renal imaging or biopsy results. ${ }^{1}$ Between 1.3 million and 2.9 million Canadians are estimated to have chronic kidney disease, based on an extrapolation of the prevalence of end-stage renal disease. ${ }^{2}$ In the United States, the 1999-2004 National Health and Nutrition Examination Survey reported a prevalence of $5.0 \%$ for stage 1 and 2 disease and $8.1 \%$ for stage 3 and 4 disease. ${ }^{3.4}$

Chronic kidney disease has been identified as a risk factor for death and cardiovascular-related morbidity and is a substantial burden on the health care system. ${ }^{1,5}$ Hemodialysis costs the Canadian health care system about $\$ 60000$ per patient per year of treatment. ${ }^{1}$ The increasing prevalence of chronic kidney disease can be attributed in part to the growing elderly population and to increasing rates of diabetes and hypertension. ${ }^{1,6,7}$

Albuminuria, which can result from abnormal vascular permeability, atherosclerosis or renal disease, has gained recognition as an independent risk factor for progressive renal dysfunction and adverse cardiovascular outcomes. ${ }^{8-10}$ In earlier stages of chronic kidney disease, albuminuria has been shown to be more predictive of renal and cardiovascular events than eGFR. ${ }^{4,9}$ This has prompted the call for a new risk stratification for cardiovascular outcomes based on both eGFR and albuminuria. ${ }^{11}$

A recent review advocated screening people for chronic kidney disease if they have hypertension, diabetes, clinically evident cardiovascular disease or a family history of kidney failure or are more than 60 years old. ${ }^{4}$ The Canadian Society of Nephrology published guidelines on the manage-
Competing interests: See end of article.

This article has been peer reviewed.

Correspondence to:

Alaa Badawi, alaa.badawi

@phac-aspc.gc.ca

CMAJ 2013. DOI:10.1503 /cmaj.120833 
ment of chronic kidney disease but did not offer guidance on screening. ${ }^{1}$ The Canadian Diabetes Association recommends annual screening with the use of an albumin:creatinine ratio, ${ }^{12}$ and the Canadian Hypertension Education Program guideline recommends urinalysis as part of the initial assessment of hypertension. ${ }^{13}$ Screening for chronic kidney disease on the basis of eGFR and albuminuria is not considered to be cost-effective in the general population, among older people or among people with hypertension. ${ }^{14}$

The objective of our study was to use direct measures (biomarkers) of kidney function to generate nationally representative, populationbased prevalence estimates of chronic kidney disease among Canadian adults overall and in clinically relevant groups.

\section{Methods}

\section{Study sample}

For our analysis, we used data from cycle 1 of the Canadian Health Measures Survey. This survey is a population-based survey designed and implemented by Statistics Canada to collect health information on Canadians aged 6-79 years. ${ }^{15,16}$ Cycle 1 of the survey was conducted between 2007 and 2009; multistage cluster sampling was used so that the data would be representative of $96.3 \%$ of Canadians when weights were applied. A Statistics Canada interviewer administered a detailed in-home health question-

\section{Box 1: Classification of the stages of chronic kidney disease ${ }^{* 1,23}$}

- Normal: glomerular filtration rate (GFR) $\geq 60 \mathrm{~mL} / \mathrm{min}$ per $1.73 \mathrm{~m}^{2}$ with no kidney damage

- Stage 1: normal or increased GFR ( $\geq 90 \mathrm{~mL} / \mathrm{min}$ per $\left.1.73 \mathrm{~m}^{2}\right)$ with kidney damage $\dagger$

- Stage 2: mildly decreased GFR $\left(60-89 \mathrm{~mL} / \mathrm{min}\right.$ per $\left.1.73 \mathrm{~m}^{2}\right)$ with kidney damage $\dagger$

- Stage 3: moderately decreased GFR (30-59 mL/min per $\left.1.73 \mathrm{~m}^{2}\right)$

- Stage 4: severely decreased GFR (15-29 mL/min per $\left.1.73 \mathrm{~m}^{2}\right)$

- Stage 5: kidney failure (GFR $<15 \mathrm{~mL} / \mathrm{min}$ per $\left.1.73 \mathrm{~m}^{2}\right)$

\section{Equations used to calculate estimated GFR}

Chronic Kidney Disease Epidemiology Collaboration (CKD-EPI) equation $\ddagger^{21}$ eGFR $=141 \times \min (\mathrm{Scr} / \kappa, 1)^{\alpha} \times \max (\mathrm{Scr} / \kappa, 1)^{-1.209} \times 0.993^{\text {age }} \times 1.018$ (if female) $\times 1.159$ (if black)

Modification of Diet in Renal Disease Equation $\ddagger^{3}$ eGFR $=175 \times(\mathrm{Scr})^{-1.154} \times(\text { age })^{-0.203} \times 0.742$ (if female) $\times 1.212$ (if black)

*Kidney damage or GFR $<60 \mathrm{~mL} / \mathrm{min}$ per $1.73 \mathrm{~m}^{2}$ for 3 or more months.

tPathologic abnormalities or markers of damage, including persistent proteinuria, abnormalities in urine sediment (persistent presence of erythrocytes, erythrocyte casts, leukocytes or leukocyte casts) or abnormal results in imaging studies (evidence of scarring or small kidneys on ultrasound or bilateral cystic changes consistent with polycystic kidney disease).

$\neq \mathrm{Scr}=$ serum creatinine level in $\mathrm{mg} / \mathrm{dL}$ (converted from $\mu \mathrm{mol} / \mathrm{L}$ to $\mathrm{mg} / \mathrm{dL}$ by dividing value by 88.4), $\kappa=0.7$ for women and 0.9 for men, $\alpha=-0.329$ for women and -0.411 for men, $\mathrm{min}=$ minimum of $\mathrm{Scr} / \kappa$ or $1, \max =$ maximum of $\mathrm{Scr} / \mathrm{\kappa}$ or 1 . Race is either black or not black. naire. Participants were then asked to visit a mobile examination centre, where biological samples and physical measurements were taken.

Of 8772 dwellings approached, 6106 (69.6\%; 7478 individuals) agreed to participate. Of the $6604(88.3 \%)$ people who completed the inhome questionnaire, $5604(84.9 \%)$ attended a mobile clinic. ${ }^{17}$ The overall response rate was $51.7 \% .^{17}$ Residents of First Nations reserves, Crown lands, certain remote regions and institutions, and full-time members of the Canadian Forces were excluded from the survey. For our analysis, we excluded participants under 18 years of age $(n=1883)$ and pregnant women $(n=32)$, which left 3689 participants.

\section{Biomarkers and estimation of kidney function}

All biological samples and physical measurements for the survey were collected during the single visit to a mobile clinic. About $80 \mathrm{~mL}$ of blood and $70 \mathrm{~mL}$ of urine were collected and processed immediately. Both blood and urine samples were aliquoted into smaller tubes and either refrigerated or frozen. Urine creatinine levels were measured using the Jaffe method at the Institut national de santé publique du Québec. Serum creatinine levels, measured using VITROS CREA Slides (Ortho-Clinical Diagnostics), and urine albumin levels were measured at Health Canada's laboratories in Ottawa. Full details of the procedures at the mobile clinics and laboratory measurements are provided elsewhere. ${ }^{18,19}$

We followed Canadian guidelines to classify participants by stage of chronic kidney disease based on the eGFR and the presence of albuminuria, the only markers of renal pathology available. ${ }^{1}$ Albuminuria was defined as a urine albumin:creatinine ratio greater than $2.0 \mathrm{mg} / \mathrm{mmol}$ for men and greater than $2.8 \mathrm{mg} / \mathrm{mmol}$ for women. ${ }^{1}$ Missing values of urine albumin $(n=1651)$ and urine creatinine $(n=8)$, owing to a level below the lower limit of detection $(<3 \mathrm{mg} / \mathrm{L}$ for urine albumin and $<0.34 \mathrm{mmol} / \mathrm{L}$ for urine creatinine), were imputed by using a random value less than the lower limit of detection. Unless otherwise indicated, we calculated eGFR using the Chronic Kidney Disease Epidemiology Collaboration (CKD-EPI) equation, because this equation estimates the glomerular filtration rate more accurately than the Modification of Diet in Renal Disease (MDRD) equation does. ${ }^{20-22}$ For our analysis, we grouped participants with stage $4(n=14)$ and $5(n=3)$ chronic kidney disease with those who had stage 3 disease. The definitions and equations used for the stages of chronic kidney disease are presented in Box 1.,23 


\section{Cardiovascular risk factors}

We assessed the prevalence of risk factors for cardiovascular disease after excluding participants who reported having current or previous heart disease and those who were taking medication for any cardiovascular condition $(n=297)$. Participants were considered to have diabetes if they reported having received a diagnosis of diabetes (type 1 or 2 ) by a health professional, had a glycated hemoglobin concentration of $6.5 \%$ or greater or had a fasting plasma glucose level of $7 \mathrm{mmol} / \mathrm{L}$ or greater. ${ }^{24}$ Hypertension was deemed present if participants reported having received a diagnosis of "high blood pressure" by a health professional or reported using blood pressure medication in the past month.

Among participants who met the fasting criteria ( $n=1659)$, risk factors for cardiovascular disease were deemed present if the ratio of total to highdensity lipoprotein (total:HDL) cholesterol was higher than 5, the low-density lipoprotein (LDL) cholesterol level was above $3.5 \mathrm{mmol} / \mathrm{L}$, the $\mathrm{HDL}$ cholesterol was below $1.03 \mathrm{mmol} / \mathrm{L}$ for men and below $1.3 \mathrm{mmol} / \mathrm{L}$ for women, and the level of triglycerides was greater than $1.7 \mathrm{mmol} / \mathrm{L}{ }^{5}$

\section{Statistical analysis}

We calculated weighted prevalence and mean estimates using sampling weights provided by Statistics Canada that accounted for representativeness and nonresponse. ${ }^{19}$ Frequencies were reported as unweighted counts. To account for the effect of age on the prevalence of risk factors for cardiovascular disease or the progression of chronic kidney disease, estimates were agestandardized to the weighted survey population aged 18-79 (excluding pregnant women) by 20year age groups.

We followed Statistics Canada reporting guidelines and indicated where sampling variability was high. We calculated prevalence estimates with the SAS 9.3 program (SAS Institute Inc., Cary, North Carolina) using survey-specific procedures and bootstrap weights for variance estimates.

\section{Results}

\section{Chronic kidney disease}

The demographic characteristics of the study population, weighted to be representative of the Canadian adult population, are presented in Table 1.

We estimated the overall prevalence of chronic kidney disease (any stage) to be $12.5 \%$ using the Chronic Kidney Disease Epidemiology Collaboration equation and $13.4 \%$ using the Modification of Diet in Renal Disease equation (Table 2). The prevalence of stage 3-5 disease was slightly lower when estimated with the Chronic Kidney
Table 1: Demographic characteristics of survey participants $(n=3689 *)$

\begin{tabular}{|c|c|}
\hline Characteristic & $\begin{array}{c}\text { Weighted prevalence } \\
\text { or mean estimatet }(95 \% \mathrm{Cl})\end{array}$ \\
\hline Age, yr, mean & $44.7(44.5-44.9)$ \\
\hline \multicolumn{2}{|l|}{ Age group, yr, \% } \\
\hline $18-39$ & $39.5(38.9-40.0)$ \\
\hline $40-64$ & $47.9(46.5-49.2)$ \\
\hline$\geq 65$ & $12.7(11.7-13.8)$ \\
\hline \multicolumn{2}{|l|}{ Sex, \% } \\
\hline Male & $49.8(49.4-50.2)$ \\
\hline Female & $50.2(49.8-50.6)$ \\
\hline \multicolumn{2}{|l|}{ Ethnicity, $¥ \%$} \\
\hline White & $82.4(73.0-89.0)$ \\
\hline Asian§ & $9.9 \quad(5.3-17.7)$ \\
\hline Other§ & $4.8 \quad(2.7-8.5)$ \\
\hline Unknown & $2.9 \quad(2.0-4.1)$ \\
\hline \multicolumn{2}{|l|}{ Education level, \% } \\
\hline Less than secondary school & $12.8(10.3-15.8)$ \\
\hline Secondary school or graduate & $18.9(14.7-23.8)$ \\
\hline Other postsecondary & $9.4 \quad(7.4-11.9)$ \\
\hline Postsecondary graduate & $59.0(50.5-67.0)$ \\
\hline \multicolumn{2}{|l|}{ Income adequacy group, $\%$} \\
\hline Lowest & $5.1 \quad(3.4-7.5)$ \\
\hline Lower middle & $14.4(12.4-16.6)$ \\
\hline Upper middle & $32.7(29.7-35.8)$ \\
\hline Highest & $47.9(43.2-52.6)$ \\
\hline Body mass index, mean & $27.1(26.7-27.6)$ \\
\hline \multicolumn{2}{|l|}{ Physical activity, } \\
\hline Active & $20.5(16.8-24.9)$ \\
\hline Moderate & $24.7(21.8-27.8)$ \\
\hline Inactive & $54.8(48.2-61.2)$ \\
\hline \multicolumn{2}{|l|}{ Smoking status, $\%$} \\
\hline Daily smoker** & $21.8(19.2-24.6)$ \\
\hline Former daily smoker** & $27.9(24.8-31.2)$ \\
\hline Never smoked & $50.3(47.0-53.6)$ \\
\hline \multicolumn{2}{|l|}{ Has a family doctor, $† \dagger \%$} \\
\hline Yes & $84.2(80.8-87.1)$ \\
\hline No & $15.8(12.9-19.2)$ \\
\hline
\end{tabular}

Note: $\mathrm{Cl}=$ confidence interval.

*Unweighted number of participants aged 18-79 years (excluding 32 pregnant participants). tWeighted prevalence and mean estimates were calculated with the use of sampling weights provided by Statistics Canada that accounted for representativeness and nonresponse. ¥Ethnicity was collapsed into 3 groups: white, Asian (Korean, Filipino, Japanese, Chinese, South Asian, Southeast Asian, Arab and West Asian) and other (black, Latin American and mixed).

§Coefficient of variation (CV) $>25 \%$ and $<30 \%$ (all other CV values $<16 \%$ ).

ПCharacterized using a measure of the average daily energy expended during leisure activities reported by the respondent in the past 3 months, as described elsewhere. ${ }^{19}$ **Daily smoker $=$ respondents who reported smoking daily and those who reported smoking occasionally but who were former daily smokers; former daily smokers $=$ respondents who reported being nonsmokers but who were former daily smokers. Occasional smokers $(n=57)$ were not included in the calculation of smoking status owing to small numbers. Smoking exposure (average number of pack-years) was 20.7 for daily smokers and 14.0 for former daily smokers. The average time since quitting among former daily smokers was 15.9 years.

t+The concept of having a family doctor was captured by asking participants if they had a "regular" medical doctor. 
Table 2: Prevalence of chronic kidney disease among Canadian adults

\begin{tabular}{|c|c|c|}
\hline $\begin{array}{l}\text { Group; stage of chronic } \\
\text { kidney disease* } \dagger\end{array}$ & $\begin{array}{l}\text { No. of } \\
\text { participantsł }\end{array}$ & $\begin{array}{l}\text { Weighted } \\
\text { prevalence,§ } \\
\%(95 \% \mathrm{Cl})\end{array}$ \\
\hline \multicolumn{3}{|c|}{ All (CKD-EPI equation)ף $(n=3589)$} \\
\hline Normal & 3073 & $87.4(85.6-89.1)$ \\
\hline Stage 1 or 2 & 353 & $9.4 \quad(7.9-11.3)$ \\
\hline Stages 3-5 & 163 & $3.1 \quad(2.4-3.9)$ \\
\hline \multicolumn{3}{|c|}{ All (MDRD equation)** $(n=3591)$} \\
\hline Normal & 3028 & $86.6(84.7-88.3)$ \\
\hline Stage 1 or 2 & 350 & $9.4 \quad(7.8-11.2)$ \\
\hline Stages 3-5 & 213 & $4.0 \quad(3.1-5.1)$ \\
\hline \multicolumn{3}{|l|}{ Men $(n=1698)$} \\
\hline Normal & 1436 & $87.6(85.1-89.7)$ \\
\hline Stage 1 or 2 & 185 & $9.6(7.8-11.9)$ \\
\hline Stages 3-5 & 77 & $2.8(2.1-3.8)$ \\
\hline \multicolumn{3}{|l|}{ Women $(n=1891)$} \\
\hline Normal & 1637 & $87.3(85.3-89.1)$ \\
\hline Stage 1 or 2 & 168 & $9.3(7.5-11.5)$ \\
\hline Stages 3-5 & 86 & $3.4(2.3-4.9)$ \\
\hline \multicolumn{3}{|l|}{ All, age $18-40$ yr $(n=1314)$} \\
\hline Normal & 1181 & $90.2(87.8-92.2)$ \\
\hline Stage 1 or 2 & 131 & $9.6(7.6-11.9)$ \\
\hline Stages 3-5 & 2 & NA $\ddagger$ \\
\hline \multicolumn{3}{|l|}{ All, age $40-64$ yr $(n=1593)$} \\
\hline Normal & 1428 & $90.0(87.2-92.3)$ \\
\hline Stage 1 or 2 & 138 & $8.6 \quad(6.6-11.2)$ \\
\hline Stages 3-5 & 27 & $1.3 \quad(0.7-2.7) \S \S$ \\
\hline \multicolumn{3}{|l|}{ All, age $\geq 65$ yr $(n=682)$} \\
\hline Normal & 464 & $69.2(65.7-72.5)$ \\
\hline Stage 1 or 2 & 84 & $12.2(9.6-15.5)$ \\
\hline Stages 3-5 & 134 & $18.6(14.2-23.9)$ \\
\hline \multicolumn{3}{|c|}{$\begin{array}{l}\text { All, without diabetes or hypertensiontt } \\
(n=2730)\end{array}$} \\
\hline Normal & 2450 & $90.3(88.0-92.2)$ \\
\hline Stage 1 or 2 & 231 & $8.4 \quad(6.9-10.2)$ \\
\hline Stages 3-5 & 49 & $1.3(0.7-2.4) \S \S$ \\
\hline
\end{tabular}

Note: $\mathrm{Cl}=$ confidence interval, CKD-EPI = Chronic Kidney Disease Epidemiology Collaboration, MDRD $=$ Modification of Diet in Renal Disease, NA = not available.

* See Box 1 for classification of the stages of chronic kidney disease.

tMissing observations $=100$ (owing to missing values for serum creatinine).

fUnweighted numbers of participants aged 18-79 years (excluding pregnant women).

§Weighted prevalence was calculated with the use of sampling weights provided by Statistics Canada that accounted for representativeness and nonresponse.

qUnweighted numbers of participants (and weighted proportions with $95 \% \mathrm{Cls}$ ) by stage of disease according to the CKD-EPI equation are as follows: normal: $3073(87.4 \%$,

$85.6 \%-89.1 \%)$; stage 1: $238(6.9 \%, 5.7 \%-8.4 \%)$; stage 2: $115(2.5 \%, 1.9 \%-3.3 \%)$; stage 3 :

$151(2.9 \%, 2.3 \%-3.6 \%)$; stage $4: 9$ (prevalence estimate NA $\neq)$; stage $5: 3$ (prevalence estimate NA $\neq$ ).

** Unweighted numbers of participants (and weighted proportions with $95 \% \mathrm{Cls}$ ) by stage of disease according to the MDRD equation are as follows: normal: $3028(86.6 \%, 84.7 \%-88.3 \%)$; stage 1: $197(5.4 \%, 4.2 \%-7.1 \%)$; stage 2: $153(3.9 \%, 3.2 \%-4.9 \%)$; stage 3: $202(3.8 \%$,

$3.0 \%-4.8 \%$ ); stage 4: 8 (prevalence estimate NA $\neq)$; stage 5: 3 (prevalence estimate NA $\neq$ ).

t+Excludes participants with diabetes $(n=300[7.2 \%])$ and hypertension $(n=759[17.6 \%])$

as defined in Methods.

¥¥Prevalence estimate cannot be reported (coefficient of variation [CV] > 33.3\%).

$\S \S M a r g i n a l$ sampling variability $(16 \%<C V<33 \%)$; interpret with caution.
Disease Epidemiology Collaboration equation (3.1\%) than with the Modification of Diet in Renal Disease equation (4.0\%).

The distribution of stages of chronic kidney disease did not differ remarkably between men and women or between young (aged 18-40 yr) and middle-aged (aged 40-64 years) adults. The prevalence of chronic kidney disease was 3 times higher among those aged 65 or older $(30.8 \% \mathrm{v}$. $<10 \%$ among younger adults). When we excluded participants with hypertension or diabetes, the prevalence of stage 1 or 2 chronic kidney disease dropped slightly, from $9.4 \%$ to $8.4 \%$. The difference was more pronounced among those with stage 3-5 disease, dropping from $3.1 \%$ to $1.3 \%$ after we excluded those with hypertension or diabetes.

Awareness of kidney dysfunction was low: only $5.3 \%$ of those with any stage of chronic kidney disease reported ever having been told by a health professional that they had "kidney disease or dysfunction." Only $12.0 \%$ of those with stage $3-5$ disease reported the same $(15.9 \%$ of men and $8.9 \%$ of women).

\section{Hypertension and diabetes}

The age-standardized prevalence of hypertension or diabetes, or both, was significantly higher among adults with than among those without chronic kidney disease (Table 3). Despite the higher prevalence of these comorbidities among those with chronic kidney disease, $72.3 \%$ of adults with chronic kidney disease had neither hypertension nor diabetes. The trend in prevalence of hypertension and diabetes increased by stage of kidney disease when we used non-agestandardized estimates: adults with stage 3-5 chronic kidney disease had a prevalence of hypertension that was more than double the prevalence among those with stage 1 or 2 disease $(52.8 \% \mathrm{v}$. $23.0 \%)$. The same was true for the prevalence of diabetes $(23.4 \%$ v. $10.8 \%)$. Of the biomarkers for risk of cardiovascular events, elevated level of triglycerides was the only one that was significantly more prevalent among adults with than without chronic kidney disease (age-standardized prevalence $39.8 \%$ v. $21.4 \%$ ). Notable differences between those with and without chronic kidney disease were observed in age-standardized prevalence rates for high total:HDL cholesterol ratio, low HDL cholesterol level and elevated highsensitivity C-reactive protein level.

\section{Albuminuria}

About $10 \%$ of adults screened positive for albuminuria among those with a normal $(\geq 90 \mathrm{~mL} / \mathrm{min}$ per $\left.1.73 \mathrm{~m}^{2}\right)$ or mildly reduced $(60-89 \mathrm{~mL} / \mathrm{min}$ per $1.73 \mathrm{~m}^{2}$ ) eGFR (Table 4). This prevalence 
almost tripled $(27.6 \%)$ among adults with an eGFR below $60 \mathrm{~mL} / \mathrm{min}$ per $1.73 \mathrm{~m}^{2}$. Among those without hypertension or diabetes, the overall prevalence of albuminuria was $9.3 \%$. Adults with albuminuria were about 3 times more likely than those without albuminuria to have an eGFR below $60 \mathrm{~mL} / \mathrm{min}$ per $1.73 \mathrm{~m}^{2}(7.6 \%$ v. $2.3 \%)$. Of those with albuminuria, most $(67.8 \%)$ did not have hypertension or diabetes; this estimate did not change appreciably $(70.7 \%)$ when we limited the analysis to those with an eGFR of $60 \mathrm{~mL} / \mathrm{min}$ per $1.73 \mathrm{~m}^{2}$ or greater (data not shown).

\section{Interpretation}

Between 2007 and 2009, an estimated 12.5\% of adults in Canada were living with chronic kidney disease. This represents about 2.9 million Can- adian adults with any chronic kidney disease and 0.73 million with stage 3-5 disease. Our prevalence estimate for any chronic kidney disease are comparable to that of $13.1 \%{ }^{3}$ in the US (measured with use of the Modification of Diet in Renal Disease equation) but higher than other estimates from Europe $(4.7 \%-8.1 \%)$, Asia $(2.5 \%-6.8 \%)$ and Australia $(11.2 \%){ }^{25}$ The prevalence of stage 3-5 disease in our study population is lower than that estimated in the US. ${ }^{3}$ In our study, the prevalence of any chronic kidney disease was about the same for both sexes as well as for young and middle-aged adults, but it was markedly higher (about $31 \%$ ) in older age groups ( $\geq 65 \mathrm{yr}$ ), similar to the few population-based Canadian estimates for chronic kidney disease. ${ }^{8,26}$

Overall awareness of kidney dysfunction in our study was low (5.3\%). Even among those

Table 3: Age-standardized, weighted prevalence of risk factors for cardiovascular events and progression of chronic kidney disease among Canadian adults without a self-reported heart condition

Chronic kidney disease group; weighted prevalence, * \% $(95 \% \mathrm{Cl})$

\begin{tabular}{|c|c|c|c|c|}
\hline \multirow[b]{2}{*}{ Variable } & & & & \multirow[b]{2}{*}{$p_{\text {diff }}$ value $\dagger$} \\
\hline & All & No disease & Disease present & \\
\hline All participantsł & $n=3392$ & $n=2874$ & $n=423$ & \\
\hline \multicolumn{5}{|l|}{ Diabetes and hypertension§ } \\
\hline Neither & $81.1(79.5-82.6)$ & $82.5(80.8-84.1)$ & $72.3(65.7-78.8)$ & 0.01 \\
\hline Hypertension & $16.3(14.9-17.7)$ & $15.0(13.4-16.6)$ & $24.4(18.9-29.9)$ & 0.007 \\
\hline Diabetes & $6.3(4.6-7.9)$ & $5.4(4.0-6.8)$ & 10.9§§ (5.9-15.9) & 0.03 \\
\hline Both & $3.6 \S \S(2.5-4.8)$ & $2.9 \S \S(1.9-3.8)$ & $7.5 \S \S(3.6-11.4)$ & 0.03 \\
\hline Obesity (BMI > 30) & $23.0(20.2-25.9)$ & $22.2(19.1-25.2)$ & $28.1(20.5-35.6)$ & 0.1 \\
\hline Abdominal obesityql & $57.4(52.8-61.9)$ & $56.7(51.5-61.9)$ & $63.2(57.0-69.4)$ & 0.2 \\
\hline \multicolumn{5}{|l|}{ Smoking status** } \\
\hline Daily & $20.7(18.4-23.0)$ & $20.6(18.0-23.1)$ & $20.2(16.4-24.0)$ & 0.9 \\
\hline Former daily & $26.3(23.8-28.7)$ & $26.5(24.0-29.1)$ & $26.0(19.8-32.2)$ & 0.9 \\
\hline Never & $49.1(46.0-52.2)$ & $48.8(46.0-51.6)$ & $50.8(43.1-58.5)$ & 0.5 \\
\hline Lipid levelst† & $n=1659$ & $n=1428$ & $n=201$ & \\
\hline Elevated triglycerdrides (> $1.7 \mathrm{mmol} / \mathrm{L}$ ) & $23.5(19.2-27.8)$ & $21.4(17.0-25.9)$ & $39.8(27.9-51.8)$ & 0.02 \\
\hline Elevated high-sensitivity CRP (> 2 mg/L) & $35.6(32.6-38.6)$ & $34.3(31.1-37.5)$ & $43.5(33.9-53.1)$ & 0.1 \\
\hline Elevated total cholesterol ( $\geq 5 \mathrm{mmol}$ ) & $44.4(39.7-49.0)$ & $43.9(38.4-49.4)$ & $49.2(39.2-59.1)$ & 0.5 \\
\hline Elevated LDL cholesterol (> $3.5 \mathrm{mmol}$ ) & $31.1(28.0-34.3)$ & $30.8(27.0-34.7)$ & $32.9 \S \S(19.5-46.3)$ & 0.8 \\
\hline Elevated total:HDL cholesterol ratio $(>5$ ) & $16.3(13.4-19.1)$ & $14.7(11.5-18.0)$ & $28.1 \S \S(15.7-40.5)$ & 0.08 \\
\hline Low HDL cholesterolł‡ & $29.9(24.7-35.1)$ & $28.6(23.3-33.9)$ & $40.0(27.6-52.4)$ & 0.1 \\
\hline \multicolumn{5}{|c|}{ 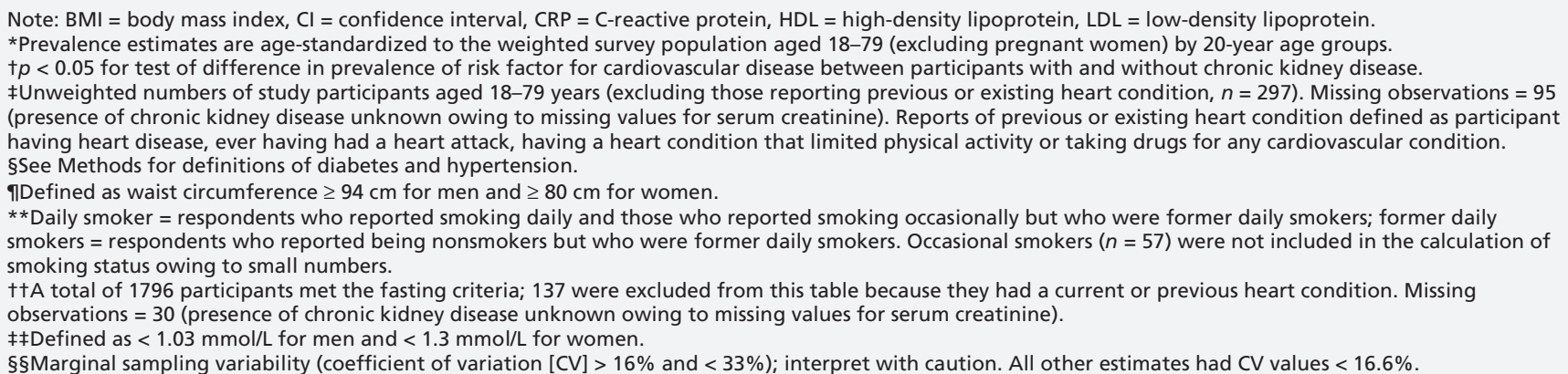 } \\
\hline
\end{tabular}


with stage 3-5 disease, when more intensive medical and lifestyle management is recommended, awareness was low (12.0\%), with more awareness among men than among women $(15.9 \%$ v. $8.9 \%)$. These percentages are slightly higher than US estimates $(11.6 \%$ of men and $5.5 \%$ of women with stage 3 disease). ${ }^{3}$

Our results support the association of diabetes, hypertension and hypertriglyceridemia with chronic kidney disease. Previous work has shown increased prevalence of hypertension and diabetes by stage of chronic kidney disease. ${ }^{27}$ Although we saw a similar trend in non-agestandardized results, interpretation is limited by the potential confounding by age, a known risk factor for chronic kidney disease.

The overall prevalence of albuminuria, an independent predictor of kidney dysfunction and cardiovascular risk, was about $10 \%$ in our study population, and was almost 3 times higher (27.6\%) among adults with an eGFR below $60 \mathrm{~mL} / \mathrm{min}$ per $1.73 \mathrm{~m}^{2}$. Our estimates of albuminuria prevalence are similar to those in the US (9.5\% overall, and $24.4 \%$ among adults with an eGFR of $30-59 \mathrm{~mL} / \mathrm{min}$ per $1.73 \mathrm{~m}^{2}$ ). ${ }^{3}$ Surprisingly, even among adults without hypertension or diabetes, the overall prevalence of albuminuria was still high $(9.3 \%)$.

Most $(92.4 \%)$ of adults with albuminuria fell into the category of stage 1 or 2 chronic kidney disease, with a normal or mildly reduced eGFR. Our findings are similar to that found in a large Canadian cohort study, in which $89 \%$ of people with proteinuria had an eGFR greater than $60 \mathrm{~mL} / \mathrm{min}$ per $1.73 \mathrm{~m}^{2} .^{8}$ This represents about $9.4 \%$ of the total population and is of particular interest, because the presence of albuminuria is an independent risk factor for cardiovascular disease. ${ }^{8}$ Adults with stage 1 or 2 chronic kidney disease may benefit from screening for albuminuria to reduce their risk of adverse outcomes; however, without other risk factors, this population

Table 4: Proportion of adults with and without albuminuria, by estimated glomerular filtration rate (eGFR) group

\begin{tabular}{|c|c|c|c|c|}
\hline \multirow{3}{*}{$\begin{array}{l}\text { Albuminuria } \\
\text { present }\end{array}$} & \multicolumn{4}{|c|}{$\begin{array}{c}\text { eGFR group, }{ }^{*} \mathrm{~mL} / \mathrm{min} \text { per } 1.73 \mathrm{~m}^{2} \\
\text { no. }(\%) \text { of participants } \dagger\end{array}$} \\
\hline & $\geq 90$ & $60-89$ & $<60$ & All \\
\hline & $238 \quad(10.1)$ & $116 \quad(8.9)$ & 39 (27.6) & $393 \quad(10.3)$ \\
\hline No & 2088 (89.9) & $984 \quad(91.1)$ & $108(72.4)$ & 3180 (89.7) \\
\hline All & $2326(100.0)$ & $1100(100.0)$ & $147(100.0)$ & $3573(100.0)$ \\
\hline \multicolumn{5}{|c|}{$\begin{array}{l}\text { * Measured by means of Chronic Kidney Disease Epidemiology Collaboration equation. } \\
\text { Missing observations }=100 \text {. } \\
\text { †Numbers are unweighted; percentages are weighted. } \\
\text { †Defined as a urine albumin:creatinine ratio of }>2.0 \mathrm{mg} / \mathrm{mmol} \text { for men or }>2.8 \mathrm{mg} / \mathrm{mmol} \text { for } \\
\text { women. Missing observations }=16 \text {. }\end{array}$} \\
\hline
\end{tabular}

may be missed. The 2 most common conditions that may prompt screening for albuminuria are diabetes and hypertension; however, only $29.3 \%$ of Canadian adults with stage 1 or 2 disease had either of these conditions. The proportion of this population with other risk factors for screening, such as a family history of kidney disease, is unknown. Given that population-based screening for kidney disease is not cost-effective, ${ }^{1,14}$ further research is required to identify populations that could benefit from screening for kidney dysfunction.

\section{Limitations}

Our study was limited by the small sample in stratified analyses, which resulted in significant sampling variability in some cases. Small cell sizes prevented reliable estimation of stagespecific risk factors. A single measure of renal biomarkers is not sufficient to diagnose chronic kidney disease. However, it is reasonable to assume that most of the people surveyed had nonacute kidney dysfunction, given that participants were well enough to travel to a mobile examination centre and participate in a number of physical measures. It is reassuring that our results are comparable to estimates from other recent studies. ${ }^{3,8}$ Self-reported disease status and medication use may have introduced measurement error in our study. However, for diabetes, we included biomarkers (fasting plasma glucose level and glycated hemoglobin concentration) in addition to self-reports to improve accuracy. Hypertension cannot be diagnosed on the basis of a single visit, even if multiple blood pressure measurements are taken; in keeping with previously published work, ${ }^{28}$ we chose not to use these measurements to assess the prevalence of hypertension in our population.

\section{Conclusion}

Our study presents biomarker-based, nationally representative prevalence estimates of chronic kidney disease in Canada. Between 2007 and 2009, $12.5 \%$ of Canadian adults (2.9 million people) were living with chronic kidney disease, an important risk factor for end-stage renal disease and all-cause mortality. About $10 \%$ of the population had stage 1 or 2 chronic kidney disease. Because most of these people did not have diabetes or hypertension, conditions most likely to prompt screening for kidney dysfunction, they may be easily missed based on current practices. A comprehensive, evidence-based Canadian guideline for screening adults for chronic kidney disease would be useful to optimize early intervention and secondary prevention of chronic kidney disease and its associated outcomes. 


\section{References}

1. Levin A, Hemmelgarn B, Culleton B, et al. Guidelines for the management of chronic kidney disease. CMAJ 2008;179:1154-62.

2. Stigant C, Stevens L, Levin A. Nephrology: 4. Strategies for the care of adults with chronic kidney disease. CMAJ 2003;168: 1553-60.

3. Coresh J, Selvin E, Stevens LA, et al. Prevalence of chronic kidney disease in the United States. JAMA 2007;298:2038-47.

4. Levey AS, Coresh J. Chronic kidney disease. Lancet 2012;379: 165-80.

5. Genest J, McPherson R, Frohlich J, et al. 2009 Canadian Cardiovascular Society/Canadian guidelines for the diagnosis and treatment of dyslipidemia and prevention of cardiovascular disease in the adult — 2009 recommendations. Can J Cardiol 2009;25:567-79.

6. Chalmers L, Kaskel FJ, Bamgbola O. The role of obesity and its bioclinical correlates in the progression of chronic kidney disease. Adv Chronic Kidney Dis 2006;13:352-64.

7. Fox CS, Larson MG, Leip EP, et al. Predictors of new-onset kidney disease in a community-based population. JAMA 2004;291: 844-50.

8. Hemmelgarn BR, Manns BJ, Lloyd A, et al. Relation between kidney function, proteinuria, and adverse outcomes. JAMA 2010;303:423-9.

9. Foster MC, Hwang SJ, Larson MG, et al. Cross-classification of microalbuminuria and reduced glomerular filtration rate: associations between cardiovascular disease risk factors and clinical outcomes. Arch Intern Med 2007;167:1386-92.

10. Astor BC, Matsushita K, Gansevoort RT, et al. Lower estimated glomerular filtration rate and higher albuminuria are associated with mortality and end-stage renal disease. A collaborative metaanalysis of kidney disease population cohorts. Kidney Int 2011; 79:1331-40.

11. Levey AS, de Jong PE, Coresh J, et al. The definition, classification, and prognosis of chronic kidney disease: a KDIGO Controversies Conference report. Kidney Int 2011;80:17-28.

12. Canadian Diabetes Association Clinical Practice Guidelines Expert Committee. Canadian Diabetes Association 2008 clinical practice guidelines for the prevention and management of diabetes in Canada. Can J Diabetes 2008;32(Suppl 1):S1-201.

13. Campbell NR, Khan NA, Hill MD, et al. 2009 Canadian Hypertension Education Program recommendations: the scientific summary — an annual update. Can J Cardiol 2009;25:271-7.

14. Manns B, Hemmelgarn B, Tonelli M, et al. Population based screening for chronic kidney disease: cost effectiveness study. BMJ 2010;341:c5869.

15. Giroux S. Canadian Health Measures Survey: sampling strategy overview. Health Rep 2007;18(Suppl):31-6.

16. Tremblay M, Wolfson M, Gorber SC. Canadian Health Measures Survey: rationale, background and overview. Health Rep 2007;18(Suppl):7-20.

17. Colapinto CK, O'Connor DL, Tremblay MS. Folate status of the population in the Canadian Health Measures Survey. CMAJ 2011;183:E100-06.

18. Bryan S, St-Denis M, Wojtas D. Canadian Health Measures Survey: clinic operations and logistics. Health Rep 2007;18(Suppl):53-70.

19. Canadian Health Measures Survey: data user guide (cycle 1). Ottawa (ON): Statistics Canada; 2012. Available: www.statcan .gc.ca/imdb-bmdi/document/5071_D2_T1_V1-eng.htm (accessed 2012 Mar. 15)

20. Matsushita K, Mahmoodi BK, Woodward M, et al. Comparison of risk prediction using the CKD-EPI equation and the MDRD study equation for estimated glomerular filtration rate. JAMA 2012;307:1941-51.

21. Levey AS, Stevens LA, Schmid CH, et al. A new equation to estimate glomerular filtration rate. Ann Intern Med 2009;150: 604-12.

22. National Kidney Disease Education Program. Estimating GFR. Bethesda (MD): The Program; 2012. Available: www.nkdep.nih gov/lab-evaluation/gfr/estimating.shtml (accessed 2012 Mar. 15).

23. National Kidney Foundation. K/DOQI clinical practice guidelines for chronic kidney disease: evaluation, classification, and stratification. Am J Kidney Dis 2002;39(Suppl 1):S1-266.
24. Goldenberg RM, Cheng AYY, Punthakee Z, et al. Position statement: use of glycated hemoglobin (A1C) in the diagnosis of type 2 diabetes mellitus in adults. Can J Diabetes 2011;35:247-49.

25. Zhang QL, Rothenbacher D. Prevalence of chronic kidney disease in population-based studies: systematic review. BMC Public Health 2008;8:117.

26. Garg AX, Kiberd BA, Clark WF, et al. Albuminuria and renal insufficiency prevalence guides population screening: results from the NHANES III. Kidney Int 2002;61:2165-75.

27. Wen CP, Cheng TY, Tsai MK, et al. All-cause mortality attributable to chronic kidney disease: a prospective cohort study based on 462293 adults in Taiwan. Lancet 2008;371:2173-82.

28. Riediger ND, Clara I. Prevalence of metabolic syndrome in the Canadian adult population. CMAJ 2011;183:E1127-34.

Competing interests: Phil McFarlane has received consultancy fees from Abbott, Amgen, AstraZeneca, Baxter, Biovail, Boehringer Ingelheim, Gambro, Merck, Novartis, Otsuka, Sanofi-Aventis and Takeda; speaker fees from Abbott, Biovail, Bristol-Myers Squibb, Boehringer Ingelheim, GlaxoSmithKline, Merck, Novartis, Sanofi-Aventis and Takeda; payment for the development of educational presentations from Bristol-Myers Squibb, Novartis and SanofiAventis; and payment for travel expenses from AstraZeneca, Merck and Novartis. His institution has received research grants from Abbott, Amgen, AstraZeneca, Biovail, Boehringer Ingelheim, GlaxoSmithKline, Novartis, Novo Nordisk, Ortho Biotech, Otsuka, Reata and Sanofi-Aventis. No competing interests declared by Paul Arora, Priya Vasa, Darren Brenner, Karl Iglar, Howard Morrison and Alaa Badawi.

Affiliations: From the Division of Science and Technology, Laboratory for Foodborne Zoonoses (Arora, Badawi), Public Health Agency of Canada, Toronto, Ont.; the Division of Epidemiology (Arora, Brenner), Dalla Lana School of Public Health, University of Toronto, Toronto, Ont.; the Department of Family and Community Medicine (Vasa), University of Toronto, Toronto, Ont.; the Departments of Family and Community Medicine (Vasa, Iglar) and Medicine (McFarlane), St. Michael's Hospital, Toronto, Ont.; and the Science Integration Division, Social Determinants and Science Integration Directorate, Health Promotion and Chronic Disease Prevention Branch (Morrison), Public Health Agency of Canada, Ottawa, Ont.

Contributors: All of the authors contributed to the conception and design of the study. Paul Arora, Priya Vasa and Alaa Badawi developed the overall concept of the study. Paul Arora conducted the analysis, and all of the authors assisted in the interpretation of the results. Paul Arora and Priya Vasa drafted the manuscript. All of the authors critically reviewed the manuscript and contributed substantive intellectual content. All of the authors approved the final version submitted for publication.

Funding: No direct funding was received for this study.

Acknowledgements: The authors acknowledge the excellent assistance of Client Services and Respondent Relations for the Canadian Health Measures Survey (CHMS) at Statistics Canada. They also acknowledge Statistics Canada for conducting the CHMS and making the dataset available.

Paul Arora, Howard Morrison and Alaa Badawi are supported by the Public Health Agency of Canada. Darren Brenner is supported by a Frederick Banting and Charles Best Canada Graduate Scholarship from the Canadian Institutes of Health Research. 